\title{
Effects of Climate and Agricultural Practices on Temporal Progress of Sclerotinia sclerotiorum for Soybean in Brazil
}

\author{
Gustavo Castilho Beruski1, André Belmont Pereira2 ${ }^{2}$, David Souza Jaccoud-Filho3, \\ Felipe Fadel Sartori ${ }^{3}$, Paulo Cesar Sentelhas ${ }^{1}$ \\ ${ }^{1}$ Department of Biosystems Engineering, University of Sao Paulo-ESALQ/USP, Piracicaba, Brazil \\ ${ }^{2}$ Department of Soil Science and Agricultural Engineering, State University of Ponta Grossa, Ponta Grossa, Brazil \\ ${ }^{3}$ Department of Plant Sciences and Crop Protection, State University of Ponta Grossa, Ponta Grossa, Brazil \\ Email: *andre.pereira@pq.cnpq.br
}

Received 1 March 2016; accepted 2 July 2016; published 5 July 2016

Copyright (C) 2016 by authors and Scientific Research Publishing Inc.

This work is licensed under the Creative Commons Attribution International License (CC BY).

http://creativecommons.org/licenses/by/4.0/

(c) (i) Open Access

\section{Abstract}

Currently the soybean crop is affected by the white mold (Sclerotinia sclerotiorum). The disease can reduce the crop yield and quality and decrease the prices of agricultural lands. The aim of the current research was to assess epidemiology of white mold on soybean crop grown at Arapoti, PR, Brazil, utilizing data related to agricultural practices and local meteorological factors. The experiment was conducted in a naturally infested area. The soybean crop was sown on October 18th, 2011. The experimental design adopted herein was a randomized block in a factorial combination with 4 row spacings $(0.35,0.45,0.60,0.75 \mathrm{~m})$ and 4 plant populations $(150,200,250,300$ thousand plants per hectare) and 4 replications. The temporal analysis of the epidemic was evaluated using mathematical models, such as Logistics, Monomolecular and Gompertz, in order to determine the best model that described the progress of the disease as a function of local meteorological elements. For the incidence data it has been shown that both logistic and monomolecular models were those that were best fitted to the experimental data. For severity, the best model related to the experimental data was the logistic one. Either for incidence or for severity, air temperature was considered to be the environmental factor most affecting the progress of the disease. The variability in the apparent infection rates of white mold on soybean was not affected by different row spacings and plant populations; therefore, suggesting that macroclimatic variations prevailed in such a fashion to mitigate the effect of cultural practices adopted in the field.

\section{Keywords}

Meteorological Data, Sclerotinia sclerotiorum (Lib.) de Bary, Glycine max, Row Spacing, Plant

\footnotetext{
${ }^{*}$ Corresponding author.
} 


\section{Population, Epidemiology}

\section{Introduction}

Sclerotinia sclerotiorum (Lib.) de Bary fungus is currently one of the most devastating plant pathogens. This disease has triggered great economic losses in agriculture and has been identified in each of the five continents.

Losses of yield owing to the disease caused by $S$. sclerotiorum might reach up to $100 \%$ in some cases. In crops such as soybean, yield can be compromised either by reduction in the size of the seed from the precocious maturation of infected plants or by the loss of seeds during harvest [1].

It has been estimated that average losses in the yield of soybean crop are to be about $10 \%$ to $20 \%$ due to the incidence of S. sclerotiorum. In absolute terms, such losses represent an average of $136 \mathrm{~kg} \cdot \mathrm{ha}^{-1}$, varying from 83.2 to $229 \mathrm{~kg} \cdot \mathrm{ha}^{-1}$ [2]. In the climatic conditions of Brazil, reductions in soybean yield due to such a disease vary from $11.5 \%$ to $96 \%$ [3].

White mold is an endemic disease; however, under certain climatic conditions, endemics of white mold might trigger epidemics, mainly as a result of the environmental factors related to both macro and microclimatic conditions created by the canopy [4].

The disease promoted by the $S$. sclerotiorum fungus on soybean crop features a spacial distribution pattern characterized by a cluster type [5] and its development can occur in an exponential [6] or logistic fashion [4] [7] as a function of time, which will in turn depend on the pathogen, genotype and environment interactions.

The analysis of disease severity might be carried out by means of the area under the disease progress curve [8], which is described by growth mathematical models [9]-[11].

Nelson et al. [12] verified that the Weibull model better depicted the progress of white mold on sunflower crop. On canola crop, the temporal progress of the disease best related to the Gompertz model, showing a coefficient of determination of 0.96 [13]. Harikrishnan \& Del Rio [4] determined that the logistic regression model for forecasting the risk of white mold incidence on common bean in North Dakota, USA, explained 75\% of the incidence of white mold on such a crop.

Crop management, as row spacing and plant population, considerably interfere with the microclimate of the canopy, affecting crop vulnerability to diseases in production fields. Thus the objective of the current study was to assess the epidemiology of white mold on soybean crop grown in the municipality of Arapoti, PR, Brazil, as a function of plant populations, row spacings and local meteorological variables.

\section{Material and Methods}

The experiment was carried out throughout the summer season of 2011-2012 in a naturally infested area located at Arapoti, in the region of Campos Gerais in the state of Parana (Alt. $966 \mathrm{~m}$, Lat. 24 $4^{\circ} 16^{\prime} \mathrm{S}$ and Long. $50^{\circ} 06^{\prime} \mathrm{W}$ ), Brazil. The soil type of the experimental area is Rhodic eutrophic (Alfisol $\mathrm{CEC}_{0-10 \mathrm{~cm}}=8.98 \mathrm{cmol} \cdot \mathrm{dm}^{-3}$; organic matter $_{0-10 \mathrm{~cm}}=30.89 \mathrm{~g} \cdot \mathrm{dm}^{-3}$ ). The local climate is classified as the Cfb type-humid subtropical climate according to Köppen's classification [14].

Shortly before the installation of the experiment in the field, four distinct points were collected at random with an area of $0.25 \mathrm{~m}^{2}$ at a depth of $0.05 \mathrm{~m}$ to determine the amount of sclerotium in the experimental area, which was equivalent to 31 sclerotium per square meter of land [3].

At the field trial, the soybean cultivar that was chosen was BMX Apolo RR® (indeterminate growth, and maturation stage of 5.5). This type of genotype is susceptible to white mold and it is considered to have a super precocious cycle. The sowing date was October $18^{\text {th }}$, 2011. Throughout the crop growing season, all the conventional cultural practices were adopted in compliance with the recommendation of experts, except concerning the application of chemical products to control white mold.

The experimental design adopted was a randomized block distributed in a factorial combination with 4 row spacings $(0.35,0.45,0.60,0.75 \mathrm{~m})$ and 4 plant populations $(150,200,250,300$ thousand plants per hectare), totaling 16 treatments with 4 replications. The experimental units were comprised of twelve rows with a length of $10 \mathrm{~m}$ and varying width, with spacing as a consideration.

At the experimental area, an automatic weather station from Campbell Scientific, Inc., was installed in order to monitor the local meteorological data. The sensors of this weather station were responsible for the measure- 
ment of global solar radiation (Rg), precipitation (P) air temperature $(\mathrm{T})$ and air relative humidity $(\mathrm{RH})$ on a daily basis. All sensors were connected to a data logger, model CR-1000®, from Campbell Scientific, Inc., that by means of a PC208W ${ }^{\circledR}$ program for Windows ${ }^{\circledR}$ environment was programmed to perform readings with a frequency of 60 seconds, and storing averages every 15 minutes.

In order to estimate leaf wetness duration (LWD), a series of data collected by a HMP45C (Temperature and Relative Humidity Probe) sensor was used. The estimation method to assess LWD considers the number of hours with a relative humidity above $90 \%$ (NHRH > 90\%) [15].

The assessments of incidence and severity were performed from the phenological stage R1, culminating with the beginning of flowering. From the R1 stage, the following dates for the assessments of incidence and severity were chosen during 2012: January $12^{\text {th }}$ (phenological stage R3), January $25^{\text {th }}$ (phenological stage R5.1), February $10^{\text {th }}$ (phenological stage R5.3) and February $24^{\text {th }}$ (phenological stage R5.5). Among the aforementioned dates only the first one was not utilized for statistical and epidemiological analyses, since there were no infection symptoms on the assessed plants in the field at that date, furthermore, in the period between R1 and R3 disease were also not found at the experimental site.

For the assessment of the incidence of disease, the criterion was based on the percentage of infected plants per plot. In order to quantify the severity of white mold, a diagrammatic scale proposed by Juliatti et al. [16] was used.

Epidemic temporal analysis of white mold on soybean were performed from the incidence plotting at each assessment, and accumulated severity data throughout the evaluations as a function of time, constructing then progress curves of the disease, which were analyzed by the fitting of the experimental data to the following regression models: logistic, monomolecular and Gompertz [11].

The choice for the best model was made on the plotting of the standard residue obtained by the difference between the observed and predicted disease, taking into consideration the coefficient of determination in conjunction with the simple linear regression equation, along with the existence or not of standards in the residues graph versus predicted values of the disease [10] [17] [18]. Moreover, for comparison between observed and predicted data of the disease the following statistical indices were adopted herein: mean absolute error (MAE) and root mean square error (RMSE).

A simple linear regression analysis was performed between meteorological variables and white mold progress rates from the mathematical model that better depicted the progress of the disease. Values of the Pearson correlation coefficient were utilized for identification of that variable which showed a larger variability proportion with the rate of apparent progress of the disease [19].

\section{Results}

Throughout the study on the progress of white mold on soybean crop three linearization transformations were employed, such as logistic, monomolecular and Gompertz. In order to determine the transformation that provided the best fit to the experimental data the proportion of incidence and severity of observed and estimated white mold by the logistic, monomolecular and Gompertz were correlated, taking into account different row spacings and plant populations.

For the incidence data of white mold on soybean crop the models that better corresponded to the experimental data were the logistic and monomolecular. Out of the 16 different treatments utilized in the current research 11 had the logistic model showing the highest coefficients of determination, whereas in the remaining five treatments, the experimental data correlated to the monomolecular model (Table 1).

According to Harikrishnan \& Del Rio [4], Mila et al. [7] and Weiss et al. [20] the progress of the disease caused by the $S$. sclerotiorum fungus on soybean crop was better represented by the exponential and logistic models as a function of time. On the other hand, in the current study we noticed that, taking into consideration the values of MAE and RMSE, the monomolecular model better depicted the progress of the disease in the field (Table 2). The mean coefficient of determination obtained by the monomolecular model under the incidence data of white mold for the different treatments was of 0.64 . These differences about the best model to describe the epidemiology of white mold is conditioned by the susceptibility of the soybean cultivar used and also by the weather conditions during the growing season.

Table 1 shows the coefficients of determination along with linear $\left(\mathrm{y}^{0}\right)$ and angular (r) coefficients by means of the simple linear regression between incidence of the transformed disease and time. Linear coefficient represents the initial inoculums of the disease, whereas angular coefficient of the regression equation depicts the 
Table 1. Coefficient of determination $\left(\mathrm{R}^{2}\right)$, linear $\left(\mathrm{y}^{0}\right)$ and angular $(\mathrm{r})$ coefficients of the simple linear regression equation obtained between observed and estimated values from the logistic, monomolecular and Gompertz models of incidence and severity of white mold on soybean crop grown at Arapoti, PR, Brazil, under different row spacings and plant populations.

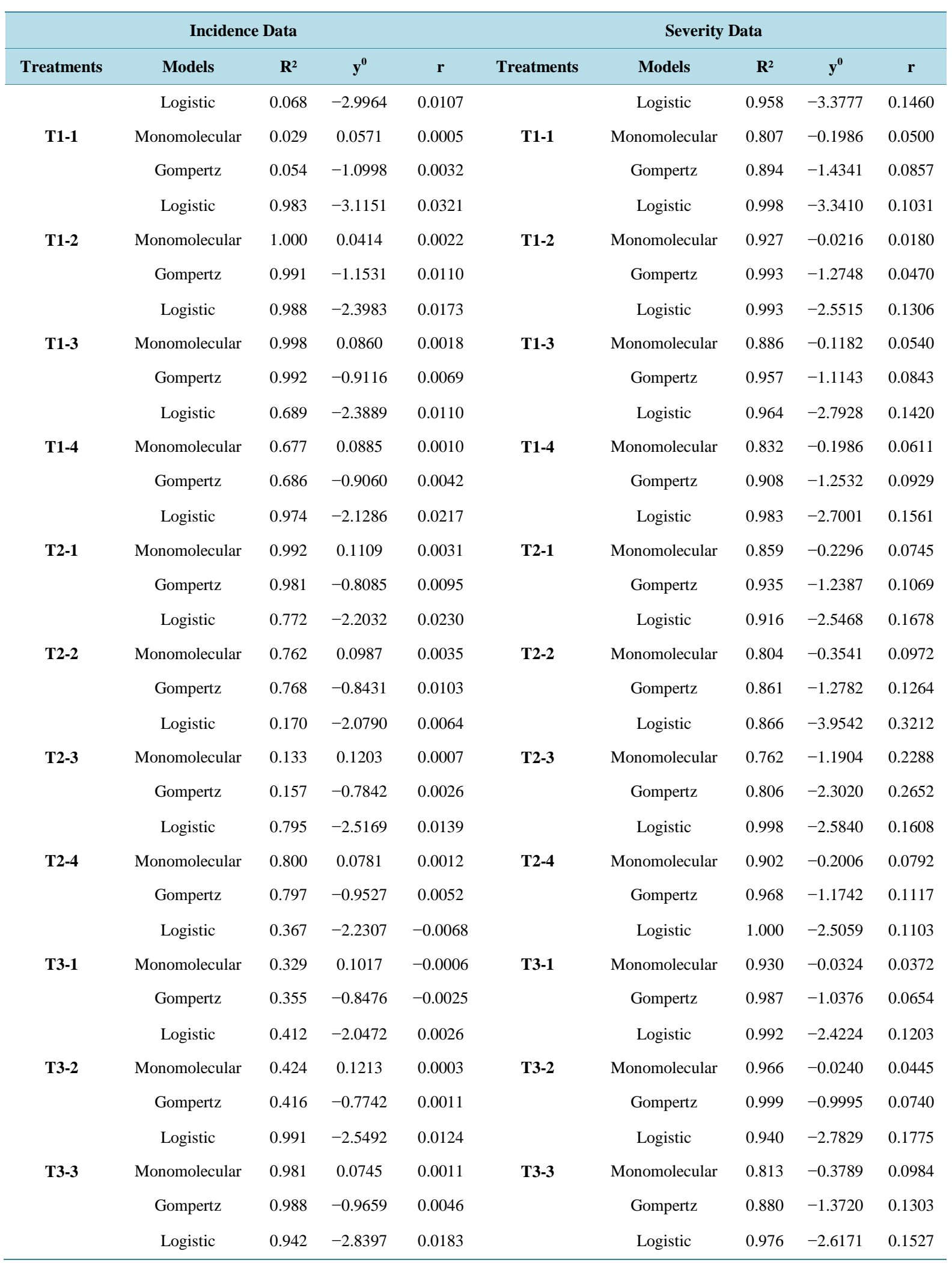




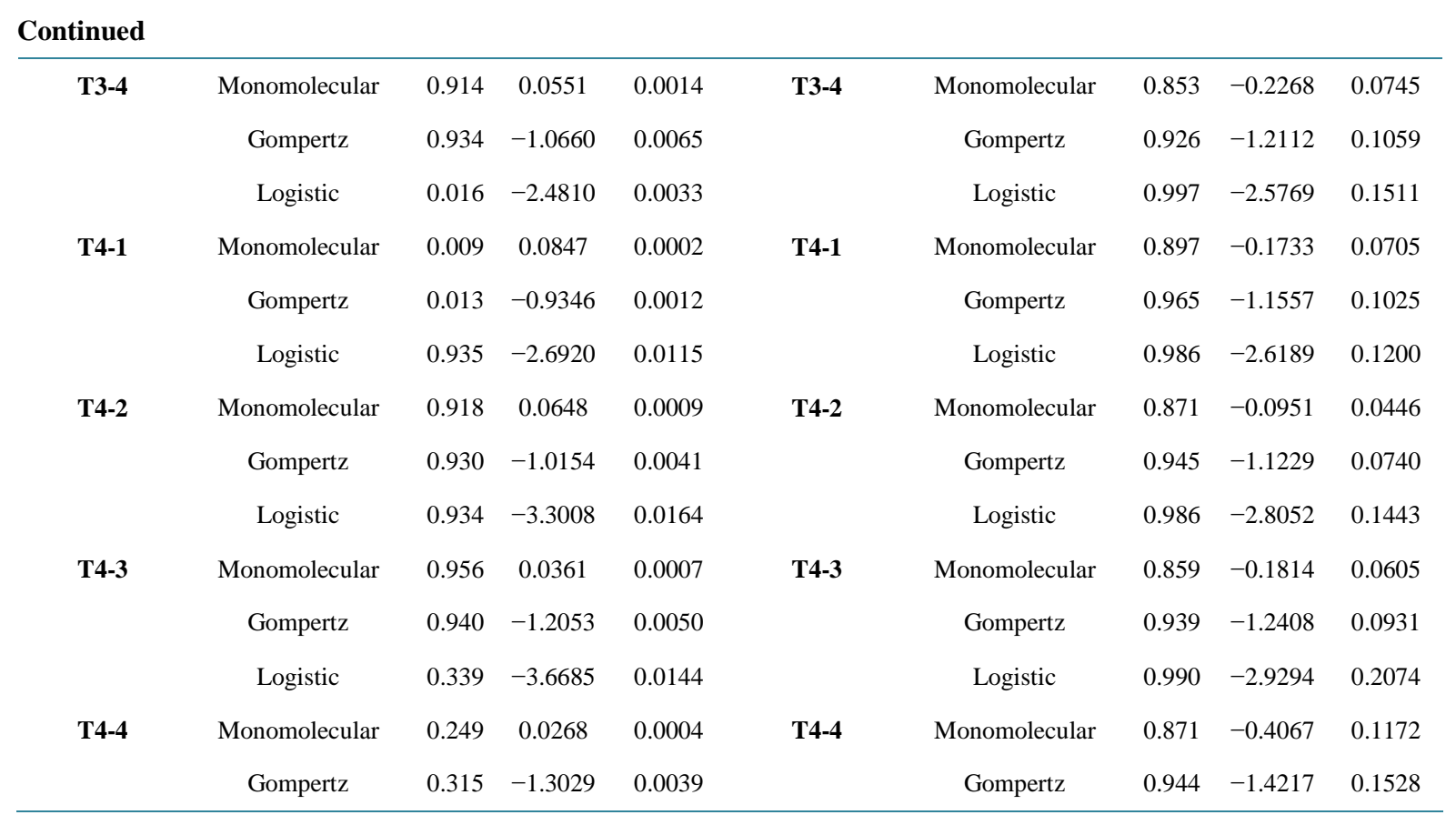

$\mathbf{R}^{\mathbf{2}}$-Coefficient of determination obtained by linear regression between the predicted and observed values of the disease; $\mathbf{y}^{\mathbf{0}}$ - Linear coefficient (a) of the linear regression equation, which represents the initial inoculum of the disease; $\mathbf{r}$-Slope (b) of simple linear regression equation, which represents the infection rate of the disease.

rate of apparent infection of the disease. The mean rate of apparent infection obtained for the different row spacings and plant populations was of 0.013 unity.day ${ }^{-1}$. Values of rate of apparent infection varied from 0.032 to -0.006 unity $\cdot d^{-1}{ }^{-1}$. Negative values of rate of apparent infection were attributed to the experimental area from which the analysis of progress of the disease was made. Analysis of progress of the disease were not always effectuated in the same plants, which contributes to a fewer number of infected plants throughout the next evaluations.

Moreover Table 1 illustrates the coefficients of determination, linear and angular coefficients of the simple linear regression equation obtained between the observed and estimated white mold severity from the logistic, monomolecular and Gompertz models under different row spacings and plant populations of soybean plants grown at Arapoti, PR, Brazil.

The logistic model showed the best fit for 15 out of 16 treatments proposed in the field trial, revealing a mean coefficient of determination corresponding to 0.971 (Table 1 ). The apparent mean infection rate (unity.day ${ }^{-1}$ ) for the disease severity data obtained under the different levels of spacing and plant population was of 0.157 unity·day ${ }^{-1}$ (Table 1). Values of apparent infection rate varied from 0.103 to 0.321 unity.day ${ }^{-1}$. The apparent infection rate variation is ascribed to variations in the spacing and plant population treatments.

The choice for the logistic model to most accurately reflect the severity data of white mold on soybean crop has been confirmed by analyzing the residue graphs obtained by the difference between observed and predicted disease severity, as well as by means of MAE and RMSE (Table 2).

Table 3 and Table 4 demonstrates the coefficients of Pearson correlation, linear and angular coefficients of the linear regression equation between the climatic factors and the rate of apparent infection of the disease (incidence) in soybean plants grown under four different row spacings and four plant populations at the municipality of Arapoti, PR, Brazil.

Mean air temperature showed the highest Pearson coefficients (R) (Table 3), with mean values of 0.64 along with a low mean standard deviation (0.06) and a low coefficient of variation (10\%). There were no effect of spacings and plant populations over the Pearson coefficients. Local meteorological variables, such as TMin, TMax and Rg were related to mean values of R corresponding to $0.37,0.41$ and 0.33 , respectively.

All Pearson coefficients obtained among the meteorological variables RHMean, RHMin, RHMax, P and LWD and the apparent infection rate of the white mold incidence data were quite low $(0.06,0.07,0.20$ and 0.08 for RHMean, RHMin, RHMax and LWD, respectively (Table 4). 
Table 2. Mean absolute error (MAE) and root mean square error (RMSE) calculated from the incidence and severity data of white mold obtained by the logistic, monomolecular and Gompertz models under the different adopted treatments.

\begin{tabular}{|c|c|c|c|c|c|c|c|}
\hline & Incidence Dat & & & & Severity Data & & \\
\hline Treatments & Models & EAM & RQEM & Treatments & Models & EAM & RQEM \\
\hline \multirow{3}{*}{ T1-1 } & Logistic & 0.0056 & 48.67 & \multirow{3}{*}{ T1-1 } & Logistic & -0.0091 & 17.16 \\
\hline & Monomolecular & -0.0005 & 47.33 & & Monomolecular & -0.0058 & 60.58 \\
\hline & Gompertz & 0.0039 & 48.05 & & Gompertz & -0.0296 & 31.18 \\
\hline \multirow{3}{*}{ T1-2 } & Logistic & 0.0000 & 4.72 & \multirow{3}{*}{ T1-2 } & Logistic & -0.0002 & 3.74 \\
\hline & Monomolecular & 0.0000 & 0.43 & & Monomolecular & -0.0007 & 22.71 \\
\hline & Gompertz & 0.0000 & 3.32 & & Gompertz & -0.0013 & 6.35 \\
\hline \multirow{3}{*}{ T1-3 } & Logistic & 0.0000 & 2.02 & \multirow{3}{*}{ T1-3 } & Logistic & -0.0069 & 6.36 \\
\hline & Monomolecular & 0.0000 & 0.85 & & Monomolecular & 0.0024 & 33.59 \\
\hline & Gompertz & 0.0000 & 1.62 & & Gompertz & -0.0179 & 16.16 \\
\hline \multirow{3}{*}{ T1-4 } & Logistic & 0.0003 & 8.08 & \multirow{3}{*}{ T1-4 } & Logistic & -0.0170 & 15.32 \\
\hline & Monomolecular & 0.0000 & 7.58 & & Monomolecular & 0.0006 & 51.15 \\
\hline & Gompertz & 0.0002 & 7.90 & & Gompertz & -0.0333 & 27.21 \\
\hline \multirow{3}{*}{ T2-1 } & Logistic & 0.0000 & 3.62 & \multirow{3}{*}{ T2-1 } & Logistic & -0.0175 & 10.87 \\
\hline & Monomolecular & 0.0000 & 1.93 & & Monomolecular & 0.0109 & 45.88 \\
\hline & Gompertz & 0.0001 & 3.00 & & Gompertz & -0.0340 & 22.48 \\
\hline \multirow{3}{*}{ T2-2 } & Logistic & 0.0010 & 12.24 & \multirow{3}{*}{ T2-2 } & Logistic & -0.0472 & 26.03 \\
\hline & Monomolecular & -0.0002 & 14.04 & & Monomolecular & 0.0237 & 68.92 \\
\hline & Gompertz & 0.0005 & 12.73 & & Gompertz & -0.0618 & 37.70 \\
\hline \multirow{3}{*}{ T2-3 } & Logistic & 0.0011 & 15.31 & \multirow{3}{*}{ T2-3 } & Logistic & -0.1463 & 62.34 \\
\hline & Monomolecular & -0.0002 & 15.12 & & Monomolecular & 0.3511 & 230.98 \\
\hline & Gompertz & 0.0007 & 15.23 & & Gompertz & -0.1713 & 75.48 \\
\hline \multirow{3}{*}{ T2-4 } & Logistic & 0.0002 & 7.78 & \multirow{3}{*}{ T2-4 } & Logistic & -0.0070 & 3.77 \\
\hline & Monomolecular & 0.0000 & 6.97 & & Monomolecular & 0.0163 & 34.06 \\
\hline & Gompertz & 0.0001 & 7.50 & & Gompertz & -0.0227 & 14.28 \\
\hline \multirow{3}{*}{ T3-1 } & Logistic & 0.0004 & 9.97 & \multirow{3}{*}{ T3-1 } & Logistic & 0.0002 & 0.28 \\
\hline & Monomolecular & 0.0000 & 9.76 & & Monomolecular & 0.0004 & 21.27 \\
\hline & Gompertz & 0.0002 & 9.89 & & Gompertz & -0.0058 & 8.11 \\
\hline \multirow{3}{*}{ T3-2 } & Logistic & 0.0001 & 3.23 & \multirow{3}{*}{ T3-2 } & Logistic & 0.0065 & 6.59 \\
\hline & Monomolecular & 0.0000 & 3.25 & & Monomolecular & 0.0024 & 13.82 \\
\hline & Gompertz & 0.0000 & 3.23 & & Gompertz & -0.0019 & 2.02 \\
\hline \multirow{3}{*}{ T3-3 } & Logistic & 0.0000 & 1.26 & \multirow{3}{*}{ T3-3 } & Logistic & -0.0438 & 23.15 \\
\hline & Monomolecular & 0.0000 & 1.88 & & Monomolecular & 0.0271 & 69.88 \\
\hline & Gompertz & 0.0000 & 1.45 & & Gompertz & -0.0632 & 36.15 \\
\hline
\end{tabular}




\section{Continued}

\begin{tabular}{|c|c|c|c|c|c|c|c|}
\hline & Logistic & 0.0001 & 4.93 & & Logistic & -0.0201 & 12.72 \\
\hline \multirow[t]{3}{*}{ T3-4 } & Monomolecular & 0.0000 & 6.30 & T3-4 & Monomolecular & 0.0102 & 46.99 \\
\hline & Gompertz & 0.0001 & 5.31 & & Gompertz & -0.0353 & 23.89 \\
\hline & Logistic & 0.0031 & 30.57 & & Logistic & -0.0071 & 4.34 \\
\hline \multirow[t]{3}{*}{ T4-1 } & Monomolecular & -0.0004 & 30.30 & T4-1 & Monomolecular & 0.0107 & 33.82 \\
\hline & Gompertz & 0.0021 & 30.43 & & Gompertz & -0.0216 & 14.80 \\
\hline & Logistic & 0.0000 & 3.30 & & Logistic & -0.0061 & 8.78 \\
\hline \multirow[t]{3}{*}{ T4-2 } & Monomolecular & 0.0000 & 3.85 & T4-2 & Monomolecular & -0.0011 & 35.51 \\
\hline & Gompertz & 0.0000 & 3.46 & & Gompertz & -0.0157 & 18.22 \\
\hline & Logistic & 0.0000 & 5.03 & & Logistic & -0.0118 & 9.74 \\
\hline \multirow[t]{3}{*}{ T4-3 } & Monomolecular & 0.0000 & 3.80 & T4-3 & Monomolecular & 0.0030 & 43.67 \\
\hline & Gompertz & 0.0000 & 4.66 & & Gompertz & -0.0272 & 21.51 \\
\hline & Logistic & 0.0008 & 24.74 & & Logistic & -0.0230 & 9.60 \\
\hline \multirow[t]{2}{*}{ T4-4 } & Monomolecular & 0.0000 & 23.60 & T4-4 & Monomolecular & 0.0543 & 53.93 \\
\hline & Gompertz & 0.0006 & 24.36 & & Gompertz & -0.0442 & 21.50 \\
\hline
\end{tabular}

Table 3. Coefficients of correlation (R), linear (a) and angular (b) coefficients of the linear regression equation between the rate of apparent infection (incidence) of white mold on soybean crop grown under different row spacings and plant populations and meteorological data collected from the weather station installed in Arapoti, PR, Brazil: mean temperature (TMean), minimum temperature (TMin), maximum temperature (TMax) $\left({ }^{\circ} \mathrm{C}\right)$ and global solar radiation $(\mathrm{Rg})\left(\mathrm{MJ} \mathrm{m}^{-2} \cdot \mathrm{dia}^{-1}\right)$.

\begin{tabular}{|c|c|c|c|c|c|c|c|c|c|c|c|c|}
\hline \multirow{3}{*}{ Treatments } & \multicolumn{12}{|c|}{ Meteorological Variable } \\
\hline & \multicolumn{3}{|c|}{ TMean } & \multicolumn{3}{|c|}{ TMin } & \multicolumn{3}{|c|}{ TMax } & \multicolumn{3}{|c|}{ Rg } \\
\hline & $\mathbf{R}$ & $\mathbf{a}$ & $\mathbf{b}$ & $\mathbf{R}$ & $\mathbf{a}$ & $\mathbf{b}$ & $\mathbf{R}$ & $\mathbf{a}$ & $\mathbf{b}$ & $\mathbf{R}$ & $\mathbf{a}$ & $\mathbf{b}$ \\
\hline T1-1 & 0.6132 & -0.6882 & 0.0365 & 0.4137 & -0.2452 & 0.0192 & 0.3534 & -0.2662 & 0.0116 & 0.3954 & 0.1216 & -0.0037 \\
\hline T1-2 & 0.7348 & -1.1550 & 0.0601 & 0.2350 & -0.1735 & 0.0149 & 0.6354 & -0.7182 & 0.0287 & 0.1320 & 0.0886 & -0.0017 \\
\hline T1-3 & 0.6803 & -1.4032 & 0.0738 & 0.3441 & -0.3609 & 0.0290 & 0.4853 & -0.7010 & 0.0291 & 0.2881 & 0.1805 & -0.0049 \\
\hline T1-4 & 0.6358 & -1.1534 & 0.0611 & 0.3939 & -0.3735 & 0.0294 & 0.3949 & -0.4889 & 0.0210 & 0.3640 & 0.1856 & -0.0054 \\
\hline T2-1 & 0.6982 & -1.9986 & 0.1049 & 0.3181 & -0.4558 & 0.0371 & 0.5249 & -1.0612 & 0.0436 & 0.2507 & 0.2295 & -0.0059 \\
\hline T2-2 & 0.7145 & -2.0363 & 0.1065 & 0.2893 & -0.4048 & 0.0335 & 0.5660 & -1.1477 & 0.0466 & 0.2095 & 0.2052 & -0.0049 \\
\hline T2-3 & 0.5984 & -1.3060 & 0.0695 & 0.4262 & -0.4945 & 0.0385 & 0.3290 & -0.4762 & 0.0211 & 0.4138 & 0.2442 & -0.0075 \\
\hline T2-4 & 0.6569 & -1.1286 & 0.0596 & 0.3726 & -0.3307 & 0.0263 & 0.4362 & -0.5183 & 0.0219 & 0.3308 & 0.1647 & -0.0047 \\
\hline T3-1 & 0.4626 & -0.7209 & 0.0392 & 0.4952 & -0.4296 & 0.0326 & 0.1148 & -0.0779 & 0.0054 & 0.5400 & 0.2120 & -0.0071 \\
\hline T3-2 & 0.5650 & -1.1879 & 0.0635 & 0.4476 & -0.5065 & 0.0391 & 0.2707 & -0.3630 & 0.0168 & 0.4518 & 0.2506 & -0.0079 \\
\hline T3-3 & 0.6527 & -1.0570 & 0.0558 & 0.3771 & -0.3163 & 0.0251 & 0.4278 & -0.4780 & 0.0202 & 0.3377 & 0.1574 & -0.0045 \\
\hline T3-4 & 0.6936 & -0.9962 & 0.0523 & 0.3248 & -0.2346 & 0.0190 & 0.5167 & -0.5233 & 0.0215 & 0.2592 & 0.1175 & -0.0030 \\
\hline T4-1 & 0.5668 & -0.8494 & 0.0454 & 0.4465 & -0.3599 & 0.0278 & 0.2737 & -0.2622 & 0.0121 & 0.4499 & 0.1781 & -0.0056 \\
\hline T4-2 & 0.6488 & -0.9073 & 0.0479 & 0.3812 & -0.2767 & 0.0219 & 0.4202 & -0.4045 & 0.0172 & 0.3440 & 0.1377 & -0.0040 \\
\hline T4-3 & 0.6787 & -0.5991 & 0.0315 & 0.3463 & -0.1557 & 0.0125 & 0.4830 & -0.2985 & 0.0124 & 0.2906 & 0.0777 & -0.0021 \\
\hline T4-4 & 0.6538 & -0.3910 & 0.0206 & 0.3760 & -0.1164 & 0.0092 & 0.4306 & -0.1778 & 0.0075 & 0.3356 & 0.0579 & -0.0016 \\
\hline
\end{tabular}


Table 4. Coefficients of correlation (R), linear (a) and angular (b) coefficients of the linear regression equation between the rate of apparent infection (incidence) of white mold on soybean crop grown under different row spacings and plant populations and meteorological data collected from the weather station installed in Arapoti, PR, Brazil: mean relative humidity (RHMean), minimum relative humidity (RHMin), maximum relative humidity (RHMax) (\%), precipitation (P) (mm·day ${ }^{-1}$ ) and leaf wetness duration (LWD) (h·day ${ }^{-1}$ ).

\begin{tabular}{|c|c|c|c|c|c|c|c|c|c|c|c|c|c|c|c|}
\hline \multirow{3}{*}{ Treatments } & \multicolumn{15}{|c|}{ Meteorological Variable } \\
\hline & \multicolumn{3}{|c|}{ RHMean } & \multicolumn{3}{|c|}{ RHMin } & \multicolumn{3}{|c|}{ RHMax } & \multicolumn{3}{|c|}{$\mathbf{P}$} & \multicolumn{3}{|c|}{ LWD } \\
\hline & $\mathbf{R}$ & $\mathbf{a}$ & $\mathbf{b}$ & $\mathbf{R}$ & $\mathbf{a}$ & b & $\mathbf{R}$ & $\mathbf{a}$ & b & $\mathbf{R}$ & $\mathbf{a}$ & b & $\mathbf{R}$ & $\mathbf{a}$ & b \\
\hline T1-1 & 0.0080 & 0.0497 & 0.0000 & 0.0945 & 0.0277 & 0.0004 & 0.1902 & 0.2804 & -0.0025 & 0.2521 & 0.0353 & 0.0002 & 0.0231 & 0.0480 & -0.0002 \\
\hline T1-2 & 0.1597 & 0.1369 & -0.0010 & 0.1334 & 0.0909 & -0.0007 & 0.2477 & 0.4722 & -0.0044 & 0.0509 & 0.0511 & 0.0000 & 0.2012 & 0.0707 & -0.0019 \\
\hline T1-3 & 0.0751 & 0.1326 & -0.0006 & 0.0038 & 0.0824 & 0.0000 & 0.2199 & 0.5729 & -0.0052 & 0.1690 & 0.0672 & 0.0002 & 0.1021 & 0.0921 & -0.0013 \\
\hline T1-4 & 0.0285 & 0.0917 & -0.0002 & 0.0649 & 0.0534 & 0.0004 & 0.1999 & 0.4701 & -0.0042 & 0.2276 & 0.0579 & 0.0002 & 0.0473 & 0.0789 & -0.0005 \\
\hline T2-1 & 0.0975 & 0.2024 & -0.0012 & 0.0365 & 0.1281 & -0.0004 & 0.2295 & 0.8202 & -0.0076 & 0.1399 & 0.0939 & 0.0002 & 0.1282 & 0.1289 & -0.0022 \\
\hline T2-2 & 0.1208 & 0.2198 & -0.0014 & 0.0714 & 0.1416 & -0.0007 & 0.2381 & 0.8376 & -0.0078 & 0.1083 & 0.0936 & 0.0002 & 0.1553 & 0.1289 & -0.0027 \\
\hline T2-3 & 0.0055 & 0.0872 & 0.0001 & 0.1127 & 0.0473 & 0.0009 & 0.1822 & 0.5274 & -0.0046 & 0.2673 & 0.0679 & 0.0003 & 0.0045 & 0.0928 & -0.0001 \\
\hline T2-4 & 0.0492 & 0.0975 & -0.0004 & 0.0344 & 0.0588 & 0.0002 & 0.2090 & 0.4599 & -0.0042 & 0.2020 & 0.0554 & 0.0002 & 0.0718 & 0.0758 & -0.0008 \\
\hline T3-1 & 0.0986 & 0.0136 & 0.0007 & 0.2454 & -0.0034 & 0.0014 & 0.1318 & 0.2966 & -0.0024 & 0.3668 & 0.0431 & 0.0003 & 0.1043 & 0.0577 & 0.0010 \\
\hline T3-2 & 0.0306 & 0.0672 & 0.0003 & 0.1502 & 0.0322 & 0.0011 & 0.1709 & 0.4849 & -0.0042 & 0.2963 & 0.0639 & 0.0003 & 0.0228 & 0.0864 & 0.0003 \\
\hline T3-3 & 0.0449 & 0.0898 & -0.0003 & 0.0407 & 0.0538 & 0.0002 & 0.2071 & 0.4306 & -0.0039 & 0.2073 & 0.0522 & 0.0002 & 0.0667 & 0.0712 & -0.0007 \\
\hline T3-4 & 0.0913 & 0.0989 & -0.0005 & 0.0287 & 0.0626 & -0.0001 & 0.2256 & 0.4059 & -0.0037 & 0.1472 & 0.0469 & 0.0001 & 0.1214 & 0.0645 & -0.0011 \\
\hline T4-1 & 0.0293 & 0.0485 & 0.0002 & 0.1483 & 0.0234 & 0.0008 & 0.1715 & 0.3467 & -0.0030 & 0.2948 & 0.0456 & 0.0002 & 0.0212 & 0.0617 & 0.0002 \\
\hline T4-2 & 0.0410 & 0.0759 & -0.0002 & 0.0464 & 0.0452 & 0.0002 & 0.2053 & 0.3695 & -0.0033 & 0.2122 & 0.0449 & 0.0002 & 0.0621 & 0.0613 & -0.0005 \\
\hline T4-3 & 0.0729 & 0.0561 & -0.0003 & 0.0013 & 0.0349 & 0.0000 & 0.2181 & 0.2436 & -0.0022 & 0.1714 & 0.0287 & 0.0001 & 0.0998 & 0.0394 & -0.0005 \\
\hline T4-4 & 0.0458 & 0.0333 & -0.0001 & 0.0389 & 0.0200 & 0.0001 & 0.2070 & 0.1590 & -0.0014 & 0.2060 & 0.0193 & 0.0001 & 0.0679 & 0.0263 & -0.0003 \\
\hline
\end{tabular}

Table 5 and Table 6 point out the Pearson's coefficients of correlation, linear and angular coefficients of the linear regression equation between the climatic factors and the rate of apparent infection of the disease (severity) in plants of soybean under four different row spacings and four plant populations in the municipality of Arapoti, PR, Brazil.

Mean air temperature affected more significantly the development of the fungus than any other environmental variables taken into account in this regression analysis study. For severity data TMax showed a high mean value of R (0.75). As opposed to TMean, TMax, the variables TMin and Rg had a low correlation with severity of white mold on soybean crop. R coefficients obtained for Tmin and Rg and the apparent infection rate was of 0.11 and 0.08 , respectively (Table 5).

Mean values of R obtained among RHMean, RHMin, RHMax, P and LWD and the apparent infection rate were of $0.21,0.26,0.20,0.08$ and 0.27 , respectively (Table 6).

\section{Discussion}

According to Jeger [6], the coefficient of determination linked to the linear regression equation between observed and predicted disease data is not sufficient to determine the model that better fits the experimental data in production fields. Thus, besides the values of $\mathrm{R}^{2}$ a residue graph obtained by the difference between observed and predicted disease data is necessary in conjunction with data dispersion analysis, expressed by the statistical parameters MAE and RMSE.

The monomolecular model takes into consideration that the increasing speed of the disease is proportional to the initial inoculums, which in turn is constituted by sclerotia present in the soil. This particular model also considers 
Table 5. Coefficients of correlation (R), linear (a) and angular (b) coefficients of the linear regression equation between the rate of apparent infection (severity) of white mold on soybean crop grown under different row spacings and plant populations and meteorological data collected from the weather station installed in Arapoti, PR, Brazil.

\begin{tabular}{|c|c|c|c|c|c|c|c|c|c|c|c|c|}
\hline \multirow{3}{*}{ Treatments } & \multicolumn{12}{|c|}{ Meteorological Variables } \\
\hline & \multicolumn{3}{|c|}{ TMean } & \multicolumn{3}{|c|}{ TMin } & \multicolumn{3}{|c|}{ TMax } & \multicolumn{3}{|c|}{ Rg } \\
\hline & $\mathbf{R}$ & $\mathbf{a}$ & b & $\mathbf{R}$ & $\mathbf{a}$ & b & $\mathbf{R}$ & $\mathbf{a}$ & b & $\mathbf{R}$ & $\mathbf{a}$ & b \\
\hline T1-1 & 0.5781 & -7.1360 & 0.3677 & 0.1725 & -1.0407 & 0.0852 & 0.6878 & -6.2400 & 0.2418 & 0.0187 & 0.2196 & 0.0019 \\
\hline T1-2 & 0.5651 & -4.1071 & 0.2121 & 0.2050 & -0.7530 & 0.0598 & 0.6659 & -3.5549 & 0.1381 & 0.0156 & 0.1766 & -0.0009 \\
\hline T1-3 & 0.6722 & -8.9167 & 0.4592 & 0.1255 & -0.6983 & 0.0666 & 0.7370 & -7.1619 & 0.2782 & 0.0462 & 0.2158 & 0.0049 \\
\hline T1-4 & 0.6566 & -8.9468 & 0.4605 & 0.1257 & -0.7310 & 0.0685 & 0.7340 & -7.3329 & 0.2845 & 0.0509 & 0.1992 & 0.0056 \\
\hline T2-1 & 0.6980 & -10.3687 & 0.5331 & 0.0892 & -0.4560 & 0.0529 & 0.7620 & -8.2939 & 0.3216 & 0.0799 & 0.1560 & 0.0095 \\
\hline T2-2 & 0.7453 & -11.7567 & 0.6039 & 0.0487 & -0.0811 & 0.0306 & 0.7904 & -9.1260 & 0.3539 & 0.1099 & 0.1023 & 0.0139 \\
\hline T2-3 & 0.8626 & -16.2946 & 0.8326 & 0.1248 & 1.8727 & -0.0936 & 0.8824 & -12.2048 & 0.4707 & 0.2573 & -0.3433 & 0.0386 \\
\hline T2-4 & 0.7254 & -11.1332 & 0.5721 & 0.0675 & -0.2594 & 0.0414 & 0.7778 & -8.7418 & 0.3390 & 0.0955 & 0.1310 & 0.0117 \\
\hline T3-1 & 0.6520 & -7.3995 & 0.3816 & 0.1555 & -0.8031 & 0.0707 & 0.7158 & -5.9491 & 0.2315 & 0.0175 & 0.2415 & 0.0016 \\
\hline T3-2 & 0.6742 & -8.5366 & 0.4399 & 0.1341 & -0.7266 & 0.0680 & 0.7322 & -6.7876 & 0.2640 & 0.0354 & 0.2353 & 0.0036 \\
\hline T3-3 & 0.7322 & -11.6387 & 0.5976 & 0.0508 & -0.1136 & 0.0322 & 0.7880 & -9.1767 & 0.3555 & 0.1124 & 0.0855 & 0.0143 \\
\hline T3-4 & 0.7035 & -10.4105 & 0.5353 & 0.0881 & -0.4408 & 0.0521 & 0.7634 & -8.2745 & 0.3210 & 0.0792 & 0.1611 & 0.0094 \\
\hline T4-1 & 0.7062 & -10.4292 & 0.5363 & 0.0878 & -0.4346 & 0.0518 & 0.7640 & -8.2635 & 0.3206 & 0.0788 & 0.1640 & 0.0093 \\
\hline T4-2 & 0.6480 & -7.8001 & 0.4020 & 0.1483 & -0.8055 & 0.0715 & 0.7193 & -6.3444 & 0.2466 & 0.0272 & 0.2300 & 0.0026 \\
\hline T4-3 & 0.6589 & -9.0797 & 0.4673 & 0.1228 & -0.7144 & 0.0677 & 0.7361 & -7.4384 & 0.2885 & 0.0537 & 0.1950 & 0.0059 \\
\hline T4-4 & 0.7768 & -13.1467 & 0.6740 & 0.0015 & 0.4210 & -0.0010 & 0.8204 & -10.1671 & 0.3934 & 0.1556 & -0.0242 & 0.0210 \\
\hline
\end{tabular}

that disease incidence on soybean crop will be related to the germination of such resistance structures producing apothecia, which will release ascospores in the air in such a way as to comprise the main via of infection of the pathogen. The large variation of $\mathrm{R}^{2}$ values might be associated with possible differences in the concentration of inoculums present in the soil.

A likely explanation for the low values of $\mathrm{R}^{2}$ is related to variability of the disease incidence as a function of different row spacing and plant population treatments (Table 3). In compliance with Harikrishnan \& Del Rio [4], the accuracy of the epidemiological models is reduced by the variation in observed values of incidence obtained in soybean production fields. The aforementioned authors report that accuracy of different models is high when the incidence of white mold is above $20 \%$ for soybean plants. Low values of $\mathrm{R}^{2}$ obtained from epidemiological analysis might be ascribed to the pathogen behavior and also to morphological aspects of the plants. However, among the most used models that study the progress of epidemics in plants exponential, monomolecular, logistic and Gompertz should be taken into account. Such models at first were not developed for phytopathological purposes and turn out to be theoretical models based on premises that do not always reflect nature [10] [17].

By analyzing the severity data the logistic model showed the best fit for 15 out of 16 treatments proposed in the field trial, revealing a mean coefficient of determination corresponding to 0.971 . Such a high accuracy indicates that $97.1 \%$ of the severity variations or fluctuations in the progress curves of white mold on soybean crop might be explained by the logistical model obtained herein. Nevertheless, such a high accuracy for the logistical model indicates that such a model also has high reliability in predicting white mold on soybean crop grown under different row spacings and plant populations at the site in study, and also influenced by weather conditions.

According to Harikrishnan \& Del Rio [21], Mila et al. [7] and Weiss et al. [20] the progress of the disease caused by the $S$. sclerotiorum fungus on soybean crop can be better represented by exponential or logistic models as a function of time. 
Table 6. Coefficients of correlation (R), linear (a) and angular (b) coefficients of the linear regression equation between the rate of apparent infection (severity) of white mold on soybean crop grown under different row spacings and plant populations and meteorological data collected from the weather station installed in Arapoti, PR, Brazil.

\begin{tabular}{|c|c|c|c|c|c|c|c|c|c|c|c|c|c|c|c|}
\hline \multirow{3}{*}{ Treatments } & \multicolumn{15}{|c|}{ Meteorological Variables } \\
\hline & \multicolumn{3}{|c|}{ RHMean } & \multicolumn{3}{|c|}{ RHMin } & \multicolumn{3}{|c|}{ RHMax } & \multicolumn{3}{|c|}{$\mathbf{P}$} & \multicolumn{3}{|c|}{ LWD } \\
\hline & $\mathbf{R}$ & $\mathbf{a}$ & b & $\mathbf{R}$ & $\mathbf{a}$ & b & $\mathbf{R}$ & $\mathbf{a}$ & b & $\mathbf{R}$ & $\mathbf{a}$ & b & $\mathbf{R}$ & $\mathbf{a}$ & b \\
\hline T1-1 & 0.0973 & 0.6496 & -0.0049 & 0.1722 & 0.6261 & -0.0072 & 0.0641 & 1.0983 & -0.0089 & 0.0070 & 0.2542 & 0.0000 & 0.1636 & 0.3617 & -0.0122 \\
\hline T1-2 & 0.0695 & 0.3232 & -0.0021 & 0.1411 & 0.3362 & -0.0035 & 0.0426 & 0.4880 & -0.0035 & 0.0392 & 0.1469 & 0.0001 & 0.1353 & 0.2088 & -0.0059 \\
\hline T1-3 & 0.1810 & 1.0993 & -0.0098 & 0.2326 & 0.8509 & -0.0104 & 0.1719 & 2.7370 & -0.0257 & 0.0495 & 0.3418 & -0.0003 & 0.2422 & 0.4819 & -0.0193 \\
\hline T1-4 & 0.1717 & 1.0753 & -0.0096 & 0.2294 & 0.8541 & -0.0105 & 0.1554 & 2.5592 & -0.0239 & 0.0472 & 0.3378 & -0.0003 & 0.2342 & 0.4772 & -0.0192 \\
\hline T2-1 & 0.2189 & 1.4091 & -0.0133 & 0.2690 & 1.0413 & -0.0134 & 0.2088 & 3.6381 & -0.0350 & 0.0866 & 0.4001 & -0.0007 & 0.2795 & 0.5638 & -0.0249 \\
\hline T2-2 & 0.2727 & 1.7850 & -0.0176 & 0.3122 & 1.2363 & -0.0165 & 0.2718 & 4.9258 & -0.0483 & 0.1301 & 0.4649 & -0.0011 & 0.3305 & 0.6534 & -0.0313 \\
\hline T2-3 & 0.4556 & 3.2321 & -0.0349 & 0.4765 & 1.9944 & -0.0300 & 0.4613 & 9.6267 & -0.0976 & 0.3037 & 0.6678 & -0.0029 & 0.5059 & 0.9357 & -0.0571 \\
\hline T2-4 & 0.2489 & 1.6138 & -0.0156 & 0.2926 & 1.1469 & -0.0151 & 0.2445 & 4.3463 & -0.0423 & 0.1102 & 0.4361 & -0.0009 & 0.3078 & 0.6136 & -0.0284 \\
\hline T3-1 & 0.1505 & 0.8319 & -0.0070 & 0.2025 & 0.6730 & -0.0077 & 0.1431 & 2.0012 & -0.0184 & 0.0188 & 0.2825 & -0.0001 & 0.2120 & 0.3983 & -0.0145 \\
\hline T3-2 & 0.1769 & 1.0397 & -0.0092 & 0.2255 & 0.8037 & -0.0096 & 0.1720 & 2.6228 & -0.0246 & 0.0417 & 0.3293 & -0.0003 & 0.2375 & 0.4639 & -0.0181 \\
\hline T3-3 & 0.2634 & 1.7388 & -0.0171 & 0.3082 & 1.2237 & -0.0164 & 0.2563 & 4.6908 & -0.0459 & 0.1266 & 0.4553 & -0.0010 & 0.3224 & 0.6408 & -0.0307 \\
\hline T3-4 & 0.2229 & 1.4269 & -0.0135 & 0.2709 & 1.0463 & -0.0135 & 0.2151 & 3.7271 & -0.0359 & 0.0883 & 0.4036 & -0.0007 & 0.2830 & 0.5684 & -0.0252 \\
\hline T4-1 & 0.2247 & 1.4349 & -0.0136 & 0.2717 & 1.0483 & -0.0135 & 0.2181 & 3.7689 & -0.0363 & 0.0890 & 0.4052 & -0.0007 & 0.2846 & 0.5706 & -0.0253 \\
\hline T4-2 & 0.1526 & 0.8832 & -0.0075 & 0.2081 & 0.7180 & -0.0084 & 0.1407 & 2.0828 & -0.0191 & 0.0250 & 0.2954 & -0.0002 & 0.2148 & 0.4171 & -0.0156 \\
\hline T4-3 & 0.1748 & 1.1015 & -0.0099 & 0.2325 & 0.8708 & -0.0108 & 0.1585 & 2.6333 & -0.0246 & 0.0503 & 0.3430 & -0.0004 & 0.2374 & 0.4846 & -0.0197 \\
\hline T4-4 & 0.3235 & 2.1826 & -0.0223 & 0.3605 & 1.4574 & -0.0204 & 0.3212 & 6.1512 & -0.0611 & 0.1805 & 0.5233 & -0.0016 & 0.3800 & 0.7353 & -0.0385 \\
\hline
\end{tabular}

Mila et al. [7], employing the logistic regression model to determine the progress of white mold on soybean, obtained a coefficient of determination of 0.65 , confirming the accuracy and reliability of the outcomes reported in the current study.

The mean rate of apparent infection for the disease severity data obtained under the different row spacings and plant populations was of 0.157 unity $\cdot d^{-1}{ }^{-1}$. The values of rate of apparent infection varied from 0.103 to 0.321 unity $\cdot$ day $^{-1}$. By analyzing the angular coefficient values of the regression equation, we verified that such coefficients were related to a standard deviation of 0.051 unity day $^{-1}$ and to a coefficient of variation of $32.54 \%$. Variations in the rate of apparent infection are associated with variations in row spacing, plant population treatments, and also with the microclimatic conditions associated to them.

The variability in the rates of apparent infection of white mold on soybean crop obtained from both incidence and severity data as a function of different row spacings and plant populations suggests that microclimatic variations occur as a result of the cultural practices adopted in this research. Thus, there is a strait relationship between the microclimatic fluctuations and rates of incidence and severity of the disease in the soybean crop.

Considering the fact that monomolecular and logistic models are those that better fit the incidence and severity data, respectively, of white mold on soybean crop for most of the cultural practices in Arapoti, PR, Brazil, such models were utilized to relate the rate of apparent infection of white mold under different environmental conditions where the experiment was conducted, with the aim of examining the contribution of each meteorological factor on the progress of the disease in the soybean plants.

The mean air temperature was the weather variable that presented the highest correlation with white mold incidence (Table 5), with mean $\mathrm{R}=0.64$. Thus, $64 \%$ of the progress of the disease suffered the influence of such a meteorological factor. There were no significant differences in $\mathrm{R}$ coefficients as a function of cultural practices. Moreover, apart from high $\mathrm{R}$ coefficients the mean standard deviation (0.06) and the coefficient of variation 
(10\%) under field conditions were low.

The highest correlation between soybean white mold and TMean data was related to the effect that such a meteorological variable has on the carpogenic germination of the sclerotia, a key element for triggering the start of epidemics of this disease on agricultural crops [22] [23]. Faced with the monitoring of minimum and mean air temperatures throughout the phenological stage considered to be susceptible to the occurrence of white mold, such temperatures remained close to $15^{\circ} \mathrm{C}$ and $20^{\circ} \mathrm{C}$, respectively. Temperatures within this range are favorable to carpogenic germination, production of apothecia and release of ascospores [20] [24] [25].

Local meteorological factors, such as minimum temperature (Tmin), maximum temperature (TMax) and global solar radiation flux density $(\mathrm{Rg})$ were yoked to an R coefficient of $0.37,0.41$ and 0.33 , respectively. Different from TMean, the variables TMin, TMax and Rg showed high values of standard deviation and also of coefficient of variation (17.42\%, 30.79\% and 30.02\%, respectively). However, just as well TMean, there were no variations in the R coefficients for TMin, TMax and Rg variables as a function of the different cultural practices adopted in the current study.

All coefficients of correlation obtained between local meteorological factors, such as RHMean, RHMin, RHMax, P and LWD, and the rate of apparent infection of white mold determined by incidence on soybean crop under different row spacings and plant populations were very low $(\mathrm{R} \leq 0.20)$. Air temperature and relative humidity have a direct effect on the development of phytopathosystems. In the current research, air temperature was the environmental factor that promoted the highest coefficients of correlation whenever data related to white mold was examined. Nevertheless, the same response was not observed when incidence data estimated by the monomolecular model was compared to climatic data of relative humidity, precipitation and leaf wetness duration, resulting in the lowest coefficients of correlation.

The highest R coefficients obtained by comparing the incidence data of white mold to the air temperature regimes might be related to a low diurnal fluctuation of such a meteorological factor, being kept within the favorable range to the development of the pathogen throughout the crop growing season, as well as during the phenological stages susceptible to the occurrence of white mold on soybean, which refer to the stages of flowering and pod formation.

The mean value of daily air temperature throughout the phenological stages susceptible to the occurrence of the disease was of $20.2^{\circ} \mathrm{C}$, while during the first, second, third and fourth assessments their values were respectively $19.7^{\circ} \mathrm{C}, 19.7^{\circ} \mathrm{C}, 20.8^{\circ} \mathrm{C}$ and $20.3^{\circ} \mathrm{C}$. According to Boland \& Hall [26] and Pennypacker \& Risius [27], the fungus in question develops better on soybean crop when the mean air temperature is found between the range of $15^{\circ} \mathrm{C}$ and $20^{\circ} \mathrm{C}$ for the region of Ontario, Canada, and between $12^{\circ} \mathrm{C}$ and $24^{\circ} \mathrm{C}$ for Pennsylvania, USA.

Air relative humidity comprises one of the most influential environmental factors that favor the occurrence of diseases in susceptible crops, including white mold. For most of the agricultural crops, there is the need for free water deposited on the leaves surface or high values of relative humidity in the air so that the infection might be successful, being therefore such a meteorological factor the key variable for the occurrence of the disease in production fields [28] [29]. However, outcomes obtained in the current research reveal a low correlation between the incidence of white mold on soybean crop and the environmental factors, such as relative humidity, precipitation and leaf wetness duration.

One straightforward explanation that can be given to the low R coefficients associated with a regression analysis study, looking at incidence data of white mold to relative humidity, precipitation and leaf wetness duration regimes, is that such independent variables were not limiting the development of $S$. sclerotiorum fungus at the site in study.

According to the Köppen climatic classification, the studied site was classified as the type of Cfb-characterrized therefore as a mesothermal climate, with high humidity and with summers showing mild temperatures [14]. The overall regime of precipitation during the most humid trimester of this region in Brazil (December, January and February) varies from 500 to $600 \mathrm{~mm}$. Therefore, the rainfall pattern at the region in study throughout the season in which the host is susceptible to the occurrence of white mold is high and well distributed, always matching the requirements of the pathogen for the infection.

Air relative humidity and leaf wetness duration on the surface of the plants are meteorological factors that are intimately related to precipitation regime. Thus, high amounts of rainfall and well distributed during the months of December, January and February at the studied site increase the rates of atmospheric humidity and enhance the time during which the leaves of the plants are covered by free water and remain wet in such a fashion as to favor the occurrence and development of the pathogen on soybean crop. 
Similar results were found by Workneh \& Yang [25], by examining the prevalence of rot brought about Sclerotinia on soybean crop grown in Central North of the USA as a function of tillage system, climate and latitudinal position. In such a research, the authors did not observe any dependence relationship between the occurrence of white mold on soybean crop and the environmental factors, such as precipitation and relative humidity in those sites where the field trials were conducted. According to the aforementioned scientists, this evidences that such meteorological factors were not limiting the occurrence of the white mold.

In compliance with our current study, Workneh \& Yang [25] reported that annual variations in air temperature were more important to the occurrence of white mold on soybean crop as opposed to the patterns of atmospheric humidity and precipitation. It is appropriate to mention that limiting factors to the occurrence of white mold on soybean crop vary from site to site and year to year as a result of the variations observed in the regime of air temperature and relative humidity at a given site.

According to Monteiro et al. [30], the differences in the values of air temperature recorded by a weather station and at the level of the canopy of a cotton crop are roughly $0.2^{\circ} \mathrm{C}$. Considering that the mean air temperature recorded by an automatic weather station in Arapoti, PR, Brazil, throughout the susceptible phenological stages to the occurrence of white mold was of $20.2^{\circ} \mathrm{C}$, such minor fluctuations of $0.2^{\circ} \mathrm{C}$ would not alter the development of the fungus at the site and crop in consideration.

Coefficients of correlation between rate of apparent infection of white mold on soybean obtained from both the incidence and severity of the disease and local meteorological factors reveal that mean air temperature affected more significantly the development of the fungus than any other environmental variable taken into account in a regression study. This might be confirmed by $\mathrm{R}$ values of the order of 0.69 . For disease severity, besides TMean, TMax showed a high correlation with the development of the disease expressed by mean values of $\mathrm{R}$ corresponding to 0.75 . Different from TMean and TMax, the climatic factors Tmin and Rg demonstrated a low correlation with the severity of white mold on soybean crop with $\mathrm{R}$ values of 0.11 and 0.08 , respectively.

Correlation coefficients determined between environmental factors and rates of apparent infection, obtained by means of data of incidence and severity of white mold on soybean crop, does not express the dependence relationship between the treatments considered in the current research and the progress curve of the disease.

Table 6 shows that the coefficients of correlation between RHMean, RHMin, RHMax, P and LWD and rates of apparent infection obtained from severity of white mold on soybean crop, under different row spacings and plant populations, were rather low. $\mathrm{R}$ mean values obtained for the relationship between the environmental factors and rates of apparent infection were of 0.21 for RHMean, 0.26 for RHMin, 0.20 for RHMax, 0.08 for P, and 0.27 for LWD.

Coefficients of correlation obtained between the severity data and climatic factors, such as relative humidity, precipitation and leaf wetness duration, were higher than those calculated from the incidence data. The increase in R coefficients taking into account severity data, suggests that relative humidity, precipitation and leaf wetness duration were those variables which substantially influenced the severity of white mold on soybean crop at the studied site.

For the incidence data relative humidity, precipitation and leaf wetness duration were not limiting to the development of S. sclerotiorum at the studied site [29]. Unlike these meteorological variables when correlated to white mold severity resulted in quite high $\mathrm{R}$ when compared to other climatic factors. Air temperature is considered to be an environmental variable that frequently is related to biological responses and is usually a limiting factor with a great influence on the epidemiology of a given disease, mainly caused by fungus and bacteria [29]. Moreover, air temperature has a regulator effect, modulating therefore the progress of the diseases [23].

The highest coefficients of correlation obtained from the comparison between severity and air temperatures (mean and maximum) might be related to a slight variation of such meteorological factors, remaining within the range favorable to the development of the pathogen throughout the crop season and primarily during the phenological stages susceptible to the occurrence of white mold on soybean crop, which refer to the flowering and pod formation [26] [27].

Independently of using incidence or severity data of white mold on soybean crop, regardless of the variations in row spacing and plant population treatments, the majority of climatic factors were not very high correlated, with coefficients of correlation very low. A similar outcome was also obtained by Lulu [18], by analyzing leaf wetness duration on grape crop and its relationship with the occurrence of mildew (Plasmopara viticola). According to the aforementioned author, correlations performed with only one meteorological factor at a time will lead to very low correlation coefficients, suggesting then that multiple regression studies could provide more sa- 
tisfactory results, due to a likely interaction existing among the conditioning factors of the disease.

In compliance with Fiorine [21], the development of plant diseases should not be conditioned by only one meteorological variable by itself, but rather by the interaction among different environmental factors plus the factors and characteristics of the plants, which certainly influence the progress of the disease in production fields.

\section{Conclusions}

Among the epidemiological models employed in this research, the monomolecular and logistic regression models proved to have more accuracy in reporting the incidence and severity of white mold on soybean crop in Southern Brazil.

Mean air temperature was closely correlated to the incidence of white mold in production fields of soybean, whereas mean and maximum air temperatures were more consistently correlated to severity of this phytopathosystem, under the environmental conditions of the current study.

The low coefficients of correlation obtained between relative humidity, precipitation and leaf wetness duration, and incidence and severity of white mold on soybean crop indicate that such climatic factors did not limit the development of the pathogen in many regions of Southern Brazil, which has similar climatic conditions of the location where the experiment was carried out.

\section{Acknowledgements}

The authors are very grateful to the following entities: Fundação Araucária, Conselho Nacional de Desenvolvimento Científico e Tecnológico, as well as Ministério da Agricultura, Pecuária e Abastecimento for the financial support provided by means of the Edital CNPq/MAPA/SDA \# 064/2008 and for the productivity fellowships in research granted to the second and last authors; Coordenação de Aperfeiçoamento de Pessoal de Nível Superior for the Master's scholarship provided to the first author; Mutuca Farm for the logistical support throughout the conduction of the field trial. Special thanks are also devoted to Dr. Aguinaldo José Nascimento for the assistance regarding the statistical analysis, as well as to MSc. Sandra Shelton from San Francisco, CA, USA, and Mr. Douglas Morrison from the University of Guelph, Ontario, Canada, for the revision of the English language of the current research.

\section{References}

[1] Morrall, R.A.A., Duczek, I.J., McKenzie, D.L. and McGee, D.C. (1976) Some Aspects of Sclerotinia sclerotiorum in Saskatchewan, 1970-75. Canadian Plant Disease Survey, 56, 56-62.

[2] Danielson, G.A., Nelson, B.D. and Helms, T.C. (2004) Effect of Sclerotinia Stem Rot on Yield of Soybean Inoculated at Different Growth Stages. Plant Disease, 88, 297-300. http://dx.doi.org/10.1094/PDIS.2004.88.3.297

[3] Jaccoud Filho, D.S., Manosso Neto, M.O., Vrisman, C.M., Henneberg, L., Grabicoski, E.M.G., Pierre, M.L.C., Berger Neto, A., Sartori, F.F., Demarch, V.B. and Rocha, C.H. (2010) Analyses, Distribuition and Quantification of White Mold in Different Growing Regions of Paraná State. In: Dalla Pria, M., Ed., Soybean Research Meeting of Brazil's Central Region, Embrapa-Soybean, Londrina, 226-228.

[4] Harikrishnan, R. and Del Río, L.E. (2008) A Logistic Regression Model for Predicting Risk of White Mold Incidence on Dry Bean in North Dakota. Plant Disease, 92, 42-46. http://dx.doi.org/10.1094/PDIS-92-1-0042

[5] Hartman, G.L., Kull, L. and Huang, Y.H. (1998) Occurrence of Sclerotinia sclerotiorum in Soybeans Fields in EastCentral Illinois and Enumeration of Inocula in Soybean Seed Lots. Plant Disease, 82, 560-564. http://dx.doi.org/10.1094/PDIS.1998.82.5.560

[6] Jeger, M.J. (1986) Asymptotic Behavior and Threshold Criteria in Model Plant Disease Epidemics. Plant Pathology, 35, 355-361. http://dx.doi.org/10.1111/j.1365-3059.1986.tb02026.x

[7] Mila, A.L., Carriquiry, A.L. and Yang, X.B. (2004) Logistic Regression Modeling of Prevalence of Soybean Sclerotinia Stem Rot in the North-Central United States. Phytopathology, 94, 102-110. http://dx.doi.org/10.1094/PHYTO.2004.94.1.102

[8] Bergamin Filho, A. and Amorim, L. (1996) Tropical Plant Disease: Epidemiology and Economic Control. Ceres, São Paulo.

[9] Berger, R.D. (1981) Comparison of the Gompertz and Logistic Equations to Describe Plant Disease Progress. Phytopathology, 71, 716-719. http://dx.doi.org/10.1094/Phyto-71-716 
[10] Campbell, C.L. and Madden, L.V. (1990) Introduction to Plant Disease Epidemiology. John Wiley \& Sons, New York.

[11] Vanderplank, J.E. (1963) Plant Disease: Epidemics and Control. Academic Press, New York, 349 p.

[12] Nelson, B.D., Hertsgaard, D.M. and Holley, R.C. (1989) Disease Progress of Sclerotinia Wilt of Sunflowers at Varying Plant Population, Inoculum Densities and Environments. Phytopathology, 79, 1358-1363. http://dx.doi.org/10.1094/Phyto-79-1358

[13] Aghajani, M.A., Safaie, N. and Alizadeh, A. (2010) Disease Progress Curves of Sclerotinia Stem Root of Canola Epidemics in Goletan Province, Iran. Journal Agriculture Science Technology, 12, 471-478.

[14] Alvares, C.A, Stape, J.L., Sentelhas, P.C., Gonçalves, J.L.M. and Sparovek, G. (2014) Köppen’s Climate Classification Map for Brazil. Meteorologische Zeitschrift, 22, 711-728. http://dx.doi.org/10.1127/0941-2948/2013/0507

[15] Sentelhas, P.C., Dalla Marta, A., Orlandini, S., Santos, E.A., Gillespie, T.J. and Gleason, M.L. (2008) Suitability of Relative Humidity as an Estimator of Leaf Wetness Duration. Agricultural and Forest Meteorology, 48, 392-400. http://dx.doi.org/10.1016/j.agrformet.2007.09.011

[16] Juliatti, F.C., Crato, F.F., Juliatti, C., Couto, K.R. and Juliatti, B.C.M. (2013) Diagramatic Scale to Evaluation of White Mold on Soybean. Bioscience Journal, 29, 676-680.

[17] Bergamin Filho, A. (1995) Disease Curve Progress. In: Bergamin Filho, A., Kimati, H. and Amorim, L., Eds., Manual of Phytopathology_Principles and Concepts, 4, Ceres, São Paulo, 627-646.

[18] Lulu, J. (2008) Leaf Wetness Duration in a "Niagara Rosada” Vineyard and Its Relationships with Downy Mildew (Plasmopara viticola) Occurrence. PhD Thesis, in Agricultural Environmental Physics, Luiz de Queiroz College of Agriculture-University of São Paulo, São Paulo, 188 p.

[19] Pedro Jr., M.J. (1983) Effects of Meteorological Factors on the Development of Coffea Leaf Rust. EPPO Bulletin, 13, 153-155. http://dx.doi.org/10.1111/j.1365-2338.1983.tb01592.x

[20] Weiss, A., Kerr, E.D. and Steadman, J.R. (1980) Temperature and Moisture Influences on Development of White Mold Disease (Sclerotinia sclerotiorum) on Great Northern Beans. Plant Disease, 64, 757-759. http://dx.doi.org/10.1094/PD-64-757

[21] Fiorine, R.A. (2006) Agrometeorological Warning-System for Controlling Fungical Diseases in "Niagara Rosada” Table-Grapes. Master Dissertation, in Subtropical and Tropical Agriculture, Agronomic Institute of Campinas, 74 p.

[22] Abawi, G.S. and Grogan, R.G. (1979) Epidemiology of Diseases Caused by Sclerotinia Species. Phytopathology, 69, 899-904. http://dx.doi.org/10.1094/Phyto-69-899

[23] Steadman, J.R. (1983) White Mold-A Serious Yield Limiting Disease of Bean. Plant Disease, 67, 346-350. http://dx.doi.org/10.1094/PD-67-346

[24] Matheron, M.E. and Porchas, M. (2005) Influence of Soil Temperature and Moisture on Eruptive Germination and Viability of Sclerotia of Sclerotinia minor and S. sclerotiorum. Plant Disease, 89, 50-54. http://dx.doi.org/10.1094/PD-89-0050

[25] Workneh, F. and Yang, X.B. (2000) Prevalence of Sclerotinia Stem Rot of Soybean in North Central United States in Relation to Tillage, Climate, and Latitudinal Positions. Phytopathology, 90, 1375-1382. http://dx.doi.org/10.1094/PHYTO.2000.90.12.1375

[26] Boland, G.J. and Hall, R. (1988) Epidemiology of Sclerotinia Stem Rot of Soybean in Ontario. Phytopathology, 78, 1241-1245. http://dx.doi.org/10.1094/Phyto-78-1241

[27] Pennypacker, B.W. and Risius, M.L. (1999) Environmental Sensitivity of Soybean Cultivars Response to Sclerotinia sclerotiorum. Phytopathology, 89, 618-622. http://dx.doi.org/10.1094/PHYTO.1999.89.8.618

[28] Huber, L. and Gillespie, T.J. (1992) Modeling Leaf Wetness in Relation to Plant Disease Epidemiology. Annual Review of Phytopathology, 30, 553-577. http://dx.doi.org/10.1146/annurev.py.30.090192.003005

[29] Sutton, J.C., Gillespie, T.J. and Hildebrans, P.D. (1984) Monitoring Weather Factors in Relation to Plant Disease. Plant Disease, 68, 78-84.

[30] Monteiro, J.E.B.A., Sentelhas, P.C. and Chiavegato, E.J. (2004) Cotton Crop Microclimate in Three Plant Population Densities. Brazilian Journal of Agrometeorology, 12, 257-264. 


\section{Submit or recommend next manuscript to SCIRP and we will provide best service for you:}

Accepting pre-submission inquiries through Email, Facebook, Linkedin, Twitter, etc A wide selection of journals (inclusive of 9 subjects, more than 200 journals)

Providing a 24-hour high-quality service

User-friendly online submission system

Fair and swift peer-review system

Efficient typesetting and proofreading procedure

Display of the result of downloads and visits, as well as the number of cited articles

Maximum dissemination of your research work

Submit your manuscript at: http://papersubmission.scirp.org/ 